\title{
Alexandre Amprimoz
}

\author{
APPRENDRE A TRAVERSER LES MURS \\ pauvre patriarche \\ sur la corde \\ si raide \\ de songes \\ pitié pour ce pantin \\ qui tremble \\ depuis toujours \\ du saint \\ il a la danse \\ et devient prisonnier \\ de sa propre \\ magie \\ chercheur d'infinis \\ il a la grâce du cœur \\ frappe à la porte \\ de la maison sans murs \\ et une clef invisible \\ lui reste dans la main
}




\section{LA COCINCHINE}

entre les palmiers nains

et ceux dont la norvège

eut la défense

un anglais

de la chine

ou un québécois

de lachine

aussi rapide

qu'un portugais

ou un viking

impromptu

et redondant

français d'indochine

avait-elle mal compris

il ne s'agissait que d'un marchand

d'étoffe qui venait de lachine

un québécois pure laine

de la côte des neiges

il n'a pas l'air chinois

ce canadien de lachine

conclut-elle 